\title{
Predicting sequelae and death after bacterial meningitis in childhood: A systematic review of prognostic studies
}

\author{
Rogier CJ de Jonge ${ }^{1,2^{*}}$, A Marceline van Furth ${ }^{1}$, Merel Wassenaar ${ }^{3}$, Reinoud JBJ Gemke ${ }^{1}$, Caroline B Terwee ${ }^{3}$
}

\begin{abstract}
Background: Bacterial meningitis (BM) is a severe infection responsible for high mortality and disabling sequelae. Early identification of patients at high risk of these outcomes is necessary to prevent their occurrence by adequate treatment as much as possible. For this reason, several prognostic models have been developed. The objective of this study is to summarize the evidence regarding prognostic factors predicting death or sequelae due to BM in children 0-18 years of age.

Methods: A search in MEDLINE and EMBASE was conducted to identify prognostic studies on risk factors for mortality and sequelae after BM in children. Selection of abstracts, full-text articles and assessment of methodological quality using the QUIPS checklist was performed by two reviewers independently. Data on prognostic factors per outcome were summarized.

Results: Of the 31 studies identified, 15 were of moderate to high quality. Due to substantial heterogeneity in study characteristics and evaluated prognostic factors, no quantitative analysis was performed. Prognostic factors found to be statistically significant in more than one study of moderate or high quality are: complaints $>48$ hours before admission, coma/impaired consciousness, (prolonged duration of) seizures, (prolonged) fever, shock, peripheral circulatory failure, respiratory distress, absence of petechiae, causative pathogen Streptococcus pneumoniae, young age, male gender, several cerebrospinal fluid (CSF) parameters and white blood cell (WBC) count.

Conclusions: Although several important prognostic factors for the prediction of mortality or sequelae after BM were identified, the inability to perform a pooled analysis makes the exact (independent) predictive value of these factors uncertain. This emphasizes the need for additional well-conducted prognostic studies.
\end{abstract}

\section{Background}

Bacterial meningitis (BM) is a severe infection of the central nervous system which occurs especially in children $<5$ years of age. Although the occurrence of negative consequences of $\mathrm{BM}$ in developed countries is strongly reduced by vaccination strategies, antibiotic treatment and good care facilities, BM is still responsible for substantial morbidity and mortality in both developing and developed countries [1-3].

The mortality rate is approximately $5 \%$, and the longterm morbidity, mainly consisting of persistent

\footnotetext{
* Correspondence: r.c.dejonge@amc.nl

'VU University Medical Center, Department of Pediatrics and Infectious
} Diseases, Amsterdam, The Netherlands neurological sequelae, is $15 \%$ [2,4-6]. Sensorineural hearing loss, seizures, motor problems, hydrocephalus and mental retardation [4,7-10], as well as more subtle outcomes like cognitive, academic and behavioral problems are observed in post-meningitis children [5,11].

In pediatric care, the goal must be to prevent these sequelae as much as possible. Therefore, early recognition of children with BM with high risk for the development of sequelae is mandatory [5,12-15]. For this reason, several studies have developed prediction models or have proposed prognostic factors for mortality or morbidity in children after BM [5-9,12-37]. The aim of the present study was to systematically review the available evidence regarding prognostic factors predicting 
death or sequelae due to $\mathrm{BM}$ in children aged 0-18 years in both developing and developed countries.

\section{Methods}

\section{Literature selection}

A systematic search of MEDLINE and EMBASE until March $20^{\text {th }} 2009$ was conducted to identify prognostic studies on mortality or various sequelae after BM in children. The search focused on BM using terms for the 10 most common causative pathogens according to the Netherlands Reference Laboratory for Bacterial Meningitis [38]. These pathogens are listed in Apendix 1. Tuberculoid meningitis or rare forms of BM were excluded. The search was refined using $\mathrm{MeSH}$ terms and text words on: morbidity, mortality, cause of death, survival rate, survival, prognos*, predict*, course*, cohort* longitudinal, cohort studies, follow-up, followup, follow up, follow-up studies. The search strategies used for Medline and Embase are included in Appendix 2. All abstracts found were screened by two reviewers independently (RdJ and MW). Those potentially eligible for inclusion were read in full text by the same two reviewers independently and subsequently discussed during a consensus meeting. Reference lists of each of the selected publications were checked to retrieve relevant publications which had not been identified by the computerized search.

The publications had to meet the following inclusion criteria, which were defined prior to the search:

- The study aimed to identify prognostic factors on mortality or various sequelae due to BM. Only studies designed as prognosis studies were included. Studies designed to analyze an associative model were excluded.

- The study was designed as a longitudinal cohort study, with at least one follow-up measurement. Both prospective and retrospective studies were included.

- BM had occurred at 0-18 years of age.

- Results were published in English as full report articles in international journals from January 1960 until March $20^{\text {th }} 2009$.

\section{Quality Assessment}

The assessment of the methodological quality was performed using the Quality In Prognosis Studies (QUIPS) tool, designed for systematic reviews of prognostic studies through international expert consensus (Table 1) [39]. This assessment was performed independently by two authors (RdJ and MW). Disagreements between both authors were discussed during a consensus meeting.

Table 1 Used (adapted) QUIPS list for scoring methodological quality of prognosis studies

\begin{tabular}{|c|c|c|c|}
\hline \multirow[t]{2}{*}{ Criteria } & \multicolumn{3}{|c|}{ Score } \\
\hline & + & $+/-$ & - \\
\hline \multicolumn{4}{|l|}{ 1. Study participation } \\
\hline - Target population & 3 & 1.5 & 0 \\
\hline - Sampling frame & 3 & 1.5 & 0 \\
\hline - Inclusion criteria & 3 & 1.5 & 0 \\
\hline - Baseline study population & 3 & 1.5 & 0 \\
\hline - Adequate study participation & 3 & 1.5 & 0 \\
\hline \multicolumn{4}{|l|}{ 2. Study attrition } \\
\hline - Proportion of population available for analysis & 5 & 2.5 & 0 \\
\hline - Outcome and prognostic factor information on those lost to follow up & 5 & 2.5 & 0 \\
\hline - Reasons and potential impact of subjects lost to follow up & 5 & 2.5 & 0 \\
\hline \multicolumn{4}{|l|}{ 3. Measurement of prognostic factors } \\
\hline - Definition of prognostic factor & 5 & 2.5 & 0 \\
\hline - Valid and reliable measurement of prognostic factor & 5 & 2.5 & 0 \\
\hline - Method and setting of prognostic factor measurement & 5 & 2.5 & 0 \\
\hline \multicolumn{4}{|l|}{ 4. Measurement of outcomes } \\
\hline - Definition of outcome & 5 & 2.5 & 0 \\
\hline - Valid and reliable measurement of outcome & 5 & 2.5 & 0 \\
\hline - Method and setting of outcome measurement & 5 & 2.5 & 0 \\
\hline \multicolumn{4}{|l|}{ 5. Statistical analysis and presentation } \\
\hline - Presentation of analytical strategy & 5 & 2.5 & 0 \\
\hline - Model development strategy & 5 & 2.5 & 0 \\
\hline - Reporting of results & 5 & 2.5 & 0 \\
\hline
\end{tabular}


The QUIPS contains six categories assessing (1) bias due to patient selection, (2) attrition, (3) measurement of prognostic factors, (4) outcome measurement, (5) confounding on statistical analysis, and (6) confounding on presentation. The items on confounding were considered irrelevant for our study because in studies regarding prognosis, the design to predict a specific outcome based on a combination of several possible prognostic factors, confounding is not an issue. The remaining 17 items of the five categories were each scored to assess the quality of the included study. High quality ('+') was scored when there was low risk of bias, moderate quality ('+/-') with moderate risk, and low quality ('-') when there was high risk of bias.

To strengthen the discriminative capacity of the QUIPS we developed a scoring algorithm. All five categories were given a maximum of 15 points each, equally divided over all items per category. For all items we assigned 5 points in case of low risk of bias and 2.5 and 0 in case of moderate and high risk of bias, respectively. Except for category 1 (patient selection bias) which contained five instead of three items. Here we assigned 3 points in case of low risk of bias and 1.5 and 0 in case of moderate and high risk of bias, respectively. A total score, with a maximum of 75 points, was calculated by summing up the scores per item. A priori, we chose to consider $\geq 60$ points ( $\geq 80 \%$ of the maximum attainable score) as high quality, between 45 and 60 points $(\geq 60 \%$ of the maximum attainable score) as moderate/high quality and $<45$ points as low quality studies.

\section{Data extraction and analysis}

Of the selected studies, data were extracted regarding study population (age at infection, country), causative pathogen, design (prospective or retrospective), duration of follow-up, method of analysis (uni- or multivariate), outcome measures and independent statistically significant prognostic factors from multivariate analysis or, if not available, from univariate analysis $(p<0.05)$. To facilitate interpretation and comparison of the results, data were categorized per outcome: (1) hearing loss, (2) mortality, (3) neurological sequelae, or (4) poor outcome when the original study made no distinction between mortality and neurological sequelae. Both short- and long-term outcomes were included.

This review did not aim to analyze original study data, therefore only the data presented in the manuscripts was used. Authors were not approached for insight in their data.

\section{Analysis of prognostic factors}

Due to heterogeneity in study design, study population and analyses of the included studies, no quantitative analysis was performed. Instead, the prognostic factors predictive for mortality or sequelae after BM were summarized per outcome category. Prognostic factors reported in different papers on the same cohort were counted once. Due to the large variety in proposed factors found, only those factors found significant $(\mathrm{p}<0.05)$ in more than one study of moderate/high quality were presented.

\section{Results}

\section{Selection of studies}

Figure 1 presents a flow chart of the study selection. The search strategy yielded 6,963 citations. Of these, 43 articles seemed to fulfill the inclusion criteria and were retrieved in full text. Two additional articles were identified by checking the reference lists. Review of these 45 articles resulted in exclusion of 14 articles not meeting the inclusion criteria. Eleven studies were excluded based on design (one letter, one validation study and nine presenting an association model instead of a prognostic model), one study dealt with diagnosis (prediction of meningitis instead of sequelae), and two studies were excluded because no differentiation was made between viral or aseptic and BM for outcome measurement. Finally, 31 articles were included and assessed on methodological quality.

\section{Methodological quality}

The results of the quality assessment are presented in Table 2. The overall quality score ranged from 17 to

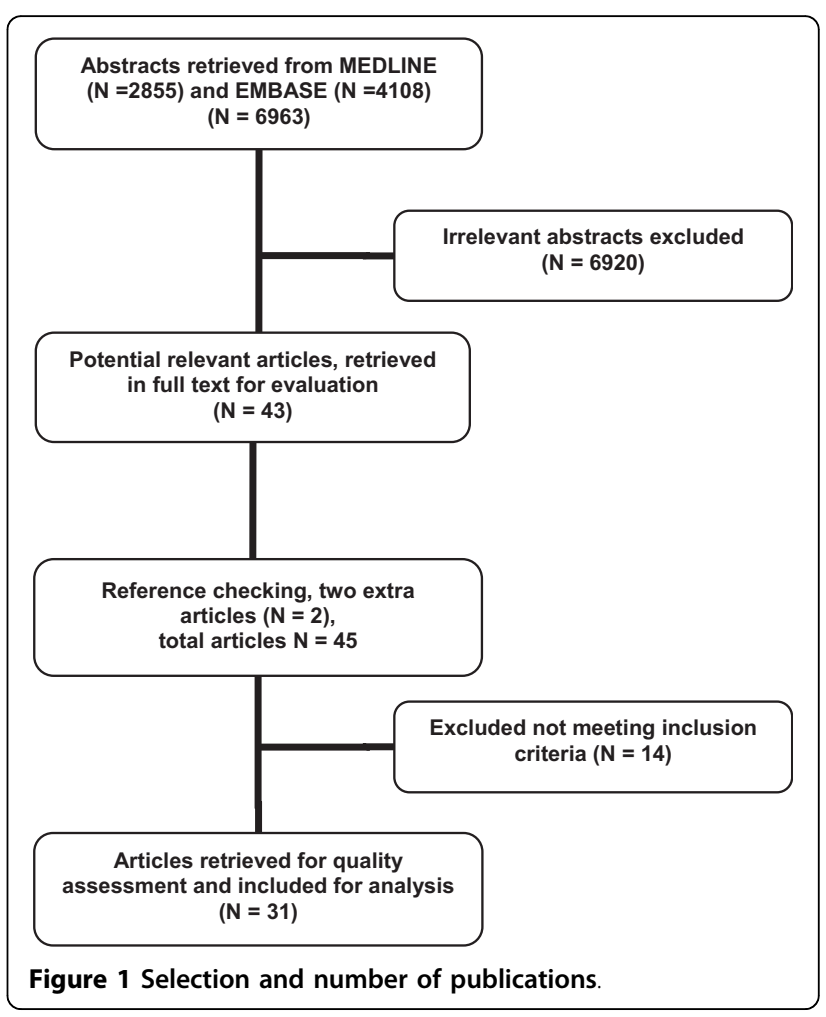


Table 2 Results of quality assessment of studies on mortality or sequelae after bacterial meningitis

\begin{tabular}{|c|c|c|c|c|c|c|c|}
\hline Study & $\begin{array}{c}\text { Study } \\
\text { participation }\end{array}$ & $\begin{array}{c}\text { Study } \\
\text { attrition }\end{array}$ & $\begin{array}{c}\text { Measurement of } \\
\text { prognostic factors }\end{array}$ & $\begin{array}{c}\text { Measurement of } \\
\text { outcomes }\end{array}$ & $\begin{array}{l}\text { Statistical analysis } \\
\text { and presentation }\end{array}$ & $\begin{array}{l}\text { Quality } \\
\text { score } \\
\text { (points) }\end{array}$ & $\begin{array}{c}\text { Quality: } \\
+=\text { high } \\
+/-= \\
\text { moderate } \\
-=\text { low }\end{array}$ \\
\hline Koomen et al., 2004 [5] & 15 & 12.5 & 10 & 12.5 & 12.5 & 62.5 & + \\
\hline Lovera et al., 2005 [33] & 13.5 & 7.5 & 12.5 & 10 & 12.5 & 56 & $+/-$ \\
\hline Roine et al., 2008 [35] & 15 & 10 & 7.5 & 7.5 & 15 & 55 & $+/-$ \\
\hline Oostenbrink et al., 2002 [21] & 15 & 7.5 & 10 & 10 & 12.5 & 55 & $+/-$ \\
\hline Pelkonen et al., 2009 [6] & 12 & 10 & 12.5 & 7.5 & 12.5 & 54.5 & $+/-$ \\
\hline Forsyth et al., 2004 [18] & 10.5 & 10 & 7.5 & 15 & 10 & 53 & $+/-$ \\
\hline Biesheuvel et al., 2006 [24] & 12 & 7.5 & 10 & 10 & 12.5 & 52 & $+/-$ \\
\hline Pagliano et al., 2007 [19] & 12 & 5 & 12.5 & 10 & 12.5 & 52 & $+/-$ \\
\hline Koomen et al., 2003 [7] & 15 & 7.5 & 10 & 7.5 & 10 & 50 & $+/-$ \\
\hline Woolley et al., 1999 [9] & 12 & 5 & 7.5 & 12.5 & 12.5 & 49.5 & $+/-$ \\
\hline Klinger et al., 2000 [31] & 13.5 & 7.5 & 7.5 & 10 & 10 & 48.5 & $+/-$ \\
\hline Singhi et al., 2007 [15] & 13.5 & 5 & 5 & 12.5 & 12.5 & 48.5 & $+/-$ \\
\hline Kornelisse et al., 1995 [8] & 10.5 & 5 & 10 & 10 & 12.5 & 48 & $+/-$ \\
\hline Fakhir et al., 1992 [27] & 12 & 7.5 & 7.5 & 12.5 & 7.5 & 47 & $+/-$ \\
\hline Akpede et al., 1999 [16] & 10.5 & 7.5 & 10 & 10 & 7.5 & 45.5 & $+/-$ \\
\hline Kaaresen et al., 1995 [29] & 13.5 & 7.5 & 7.5 & 5 & 10 & 43.5 & - \\
\hline Kutz et al., 2006 [14] & 13.5 & 5 & 7.5 & 7.5 & 10 & 43.5 & - \\
\hline Pikis et al., 1996 [20] & 13.5 & 7.5 & 7.5 & 7.5 & 7.5 & 43.5 & - \\
\hline Pomeroy et al., 1990 [34] & 15 & 5 & 5 & 10 & 7.5 & 42.5 & - \\
\hline Wasier et al., 2005 [37] & 10.5 & 5 & 7.5 & 7.5 & 10 & 40.5 & - \\
\hline Grimwood et al., 1996 [12] & 7.5 & 5 & 7.5 & 12.5 & 7.5 & 40 & - \\
\hline Edwards et al., 1985 [17] & 10.5 & 7.5 & 7.5 & 10 & 2.5 & 38 & - \\
\hline Letson et al., 1992 [32] & 10.5 & 5 & 5 & 10 & 7.5 & 38 & - \\
\hline Chao et al., 2008 [26] & 12 & 2.5 & 5 & 7.5 & 5 & 32 & - \\
\hline Johnson et al. 2007 [28] & 12 & 2.5 & 5 & 7.5 & 5 & 32 & - \\
\hline Bortolussi et al., 1978 [25] & 10.5 & 5 & 2.5 & 7.5 & 5 & 30.5 & - \\
\hline Antilla et al., 1994 [22] & 7.5 & 2.5 & 7.5 & 7.5 & 2.5 & 27.5 & - \\
\hline Kirimi et al., 2003 [30] & 7.5 & 5 & 7.5 & 2.5 & 5 & 27.5 & - \\
\hline Valmari et al., 1987 [36] & 4.5 & 2.5 & 5 & 5 & 7.5 & 24.5 & - \\
\hline Herson et al., 1977 [13] & 4.5 & 2.5 & 5 & 2.5 & 5 & 19.5 & - \\
\hline Bhat et al., 1987 [23] & 4.5 & 2.5 & 2.5 & 2.5 & 5 & 17 & - \\
\hline
\end{tabular}

62.5 points with a median score of 43.5 . Based on our cutoff of $\geq 60$ and $\geq 45$ points, respectively, one article was classified as high quality, 14 articles were classified as moderate/high quality and 16 articles as low quality studies.

Studies of moderate/high quality scored well on patient selection, outcome measurement, statistical analysis and presentation, and relatively well on prognostic factor measurement. However, many moderate/high quality studies scored poor on attrition. Studies classified as low quality scored relatively well on patient selection, but poor on all other categories. A poor score on prognostic factor measurement was often due to the fact the studies did not mention all factors considered in their analysis but presented only those factors found significant.

\section{Study characteristics}

Table 3 summarizes the study characteristics of all included publications. Studies were grouped by outcome categories and ranked by quality. Of all 31 included studies, four studies focused on hearing loss, four on mortality, five on neurological sequelae ranging from mild to severe, and another 12 studies focused on poor outcome. The remaining six studies focused on both mortality and neurological sequelae, for which results were presented separately. Therefore, these studies were included more than once. The majority of all studies $(\mathrm{n}=21)$ had a retrospective study design and 22 were conducted in developed countries. Sixteen studies performed a multivariate analysis. Although Klinger et al. [31] performed a multivariate analysis, we reported the prognostic factors based on their univariate analysis, 


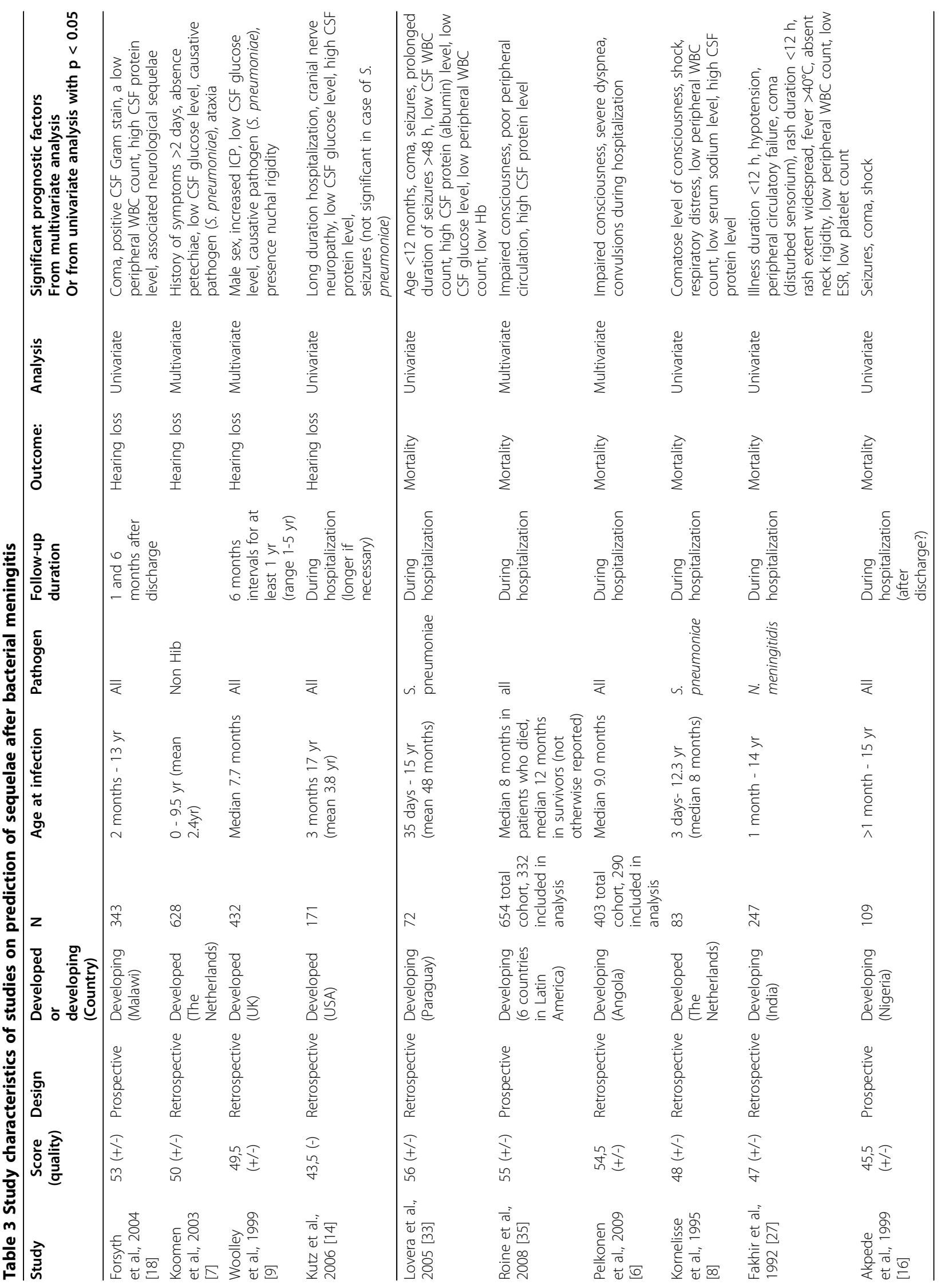




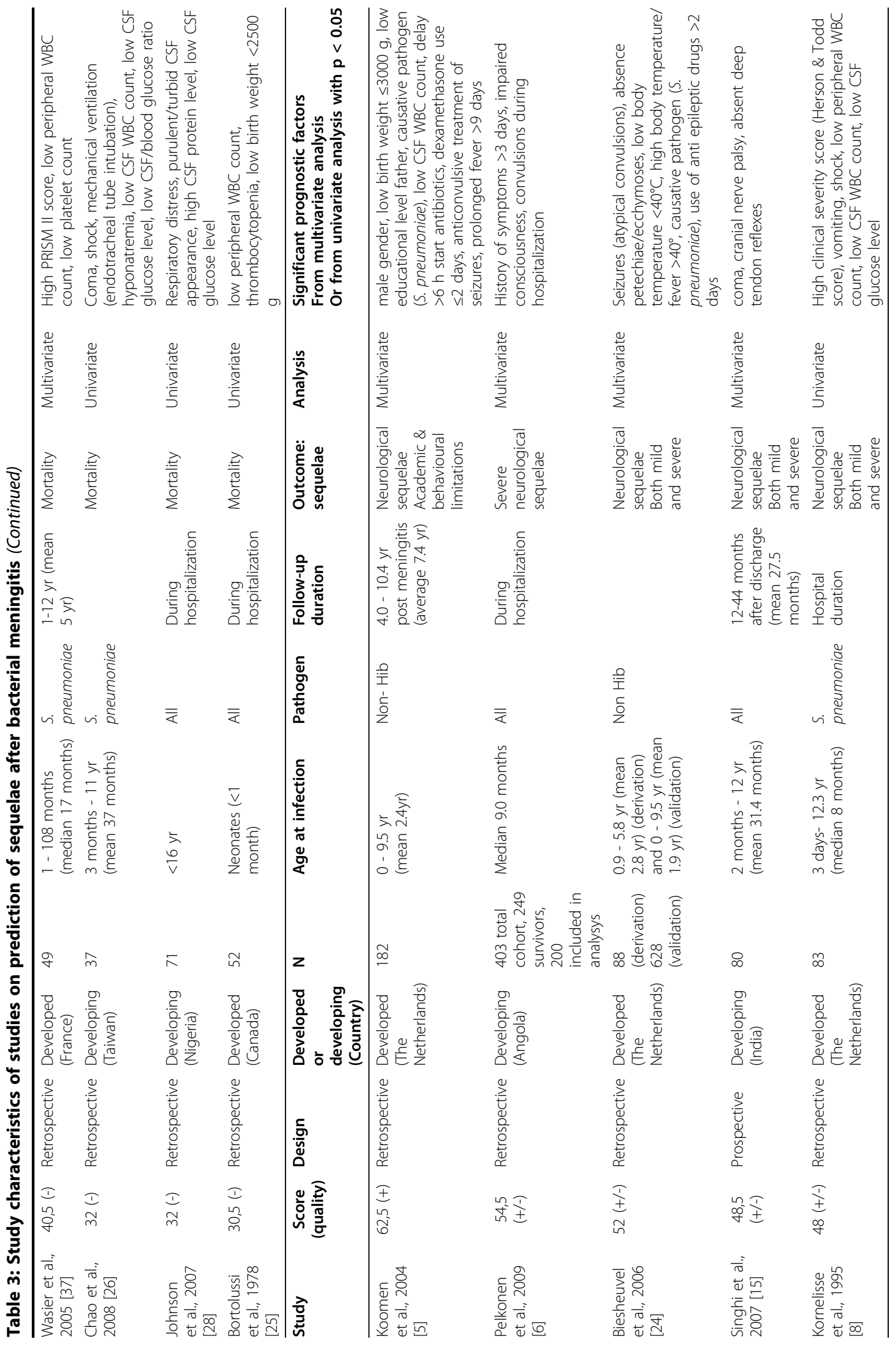




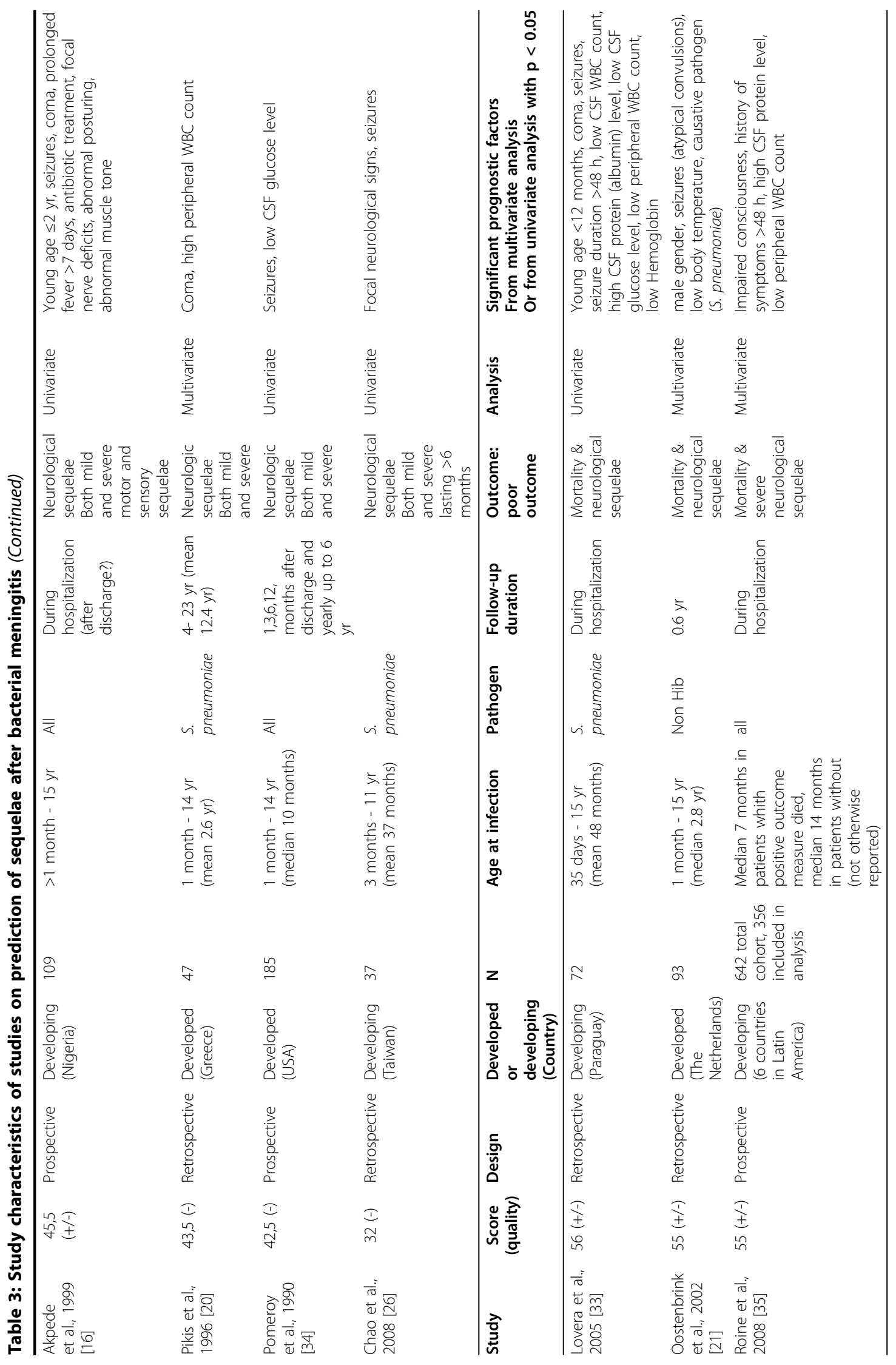




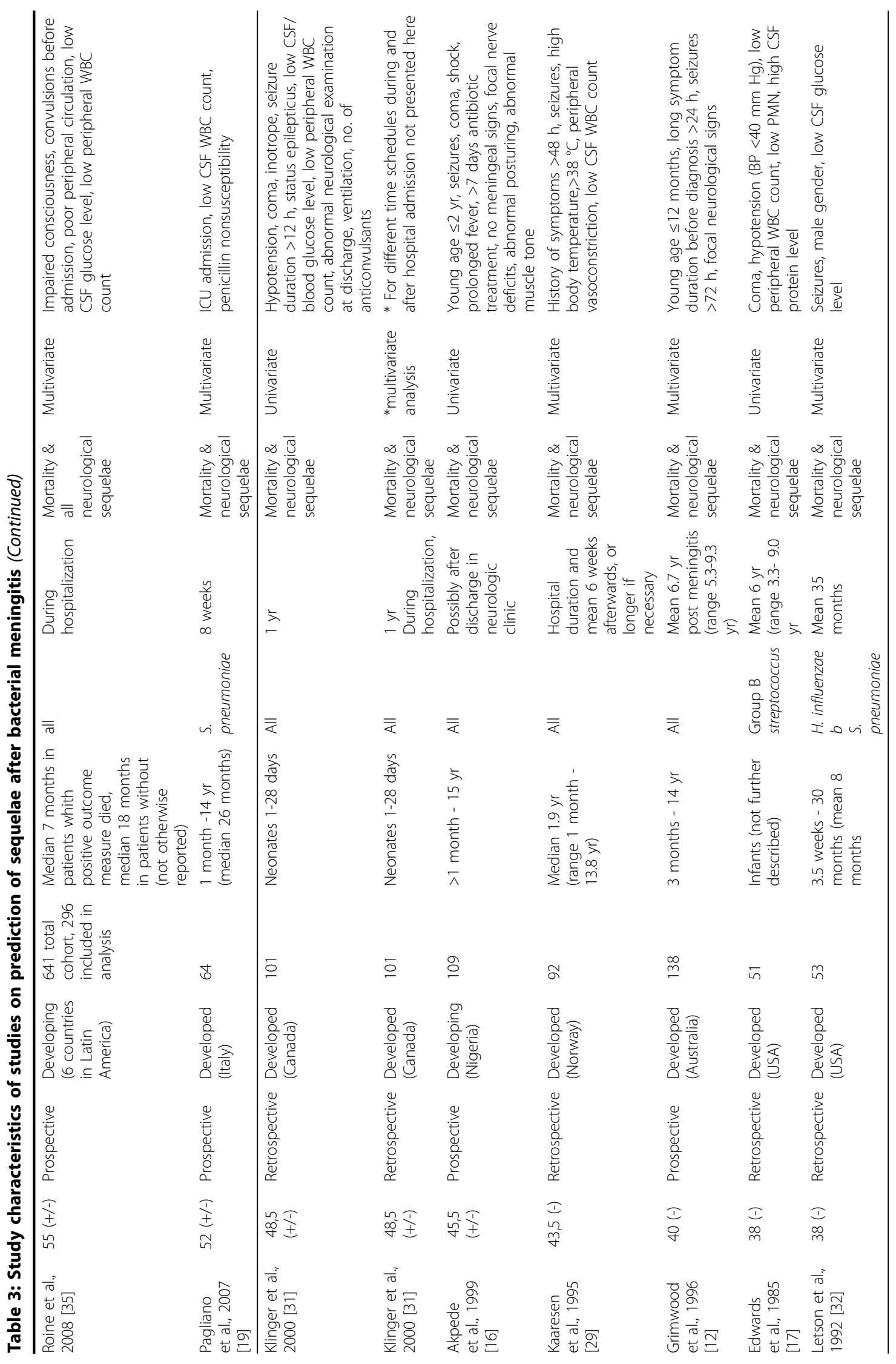




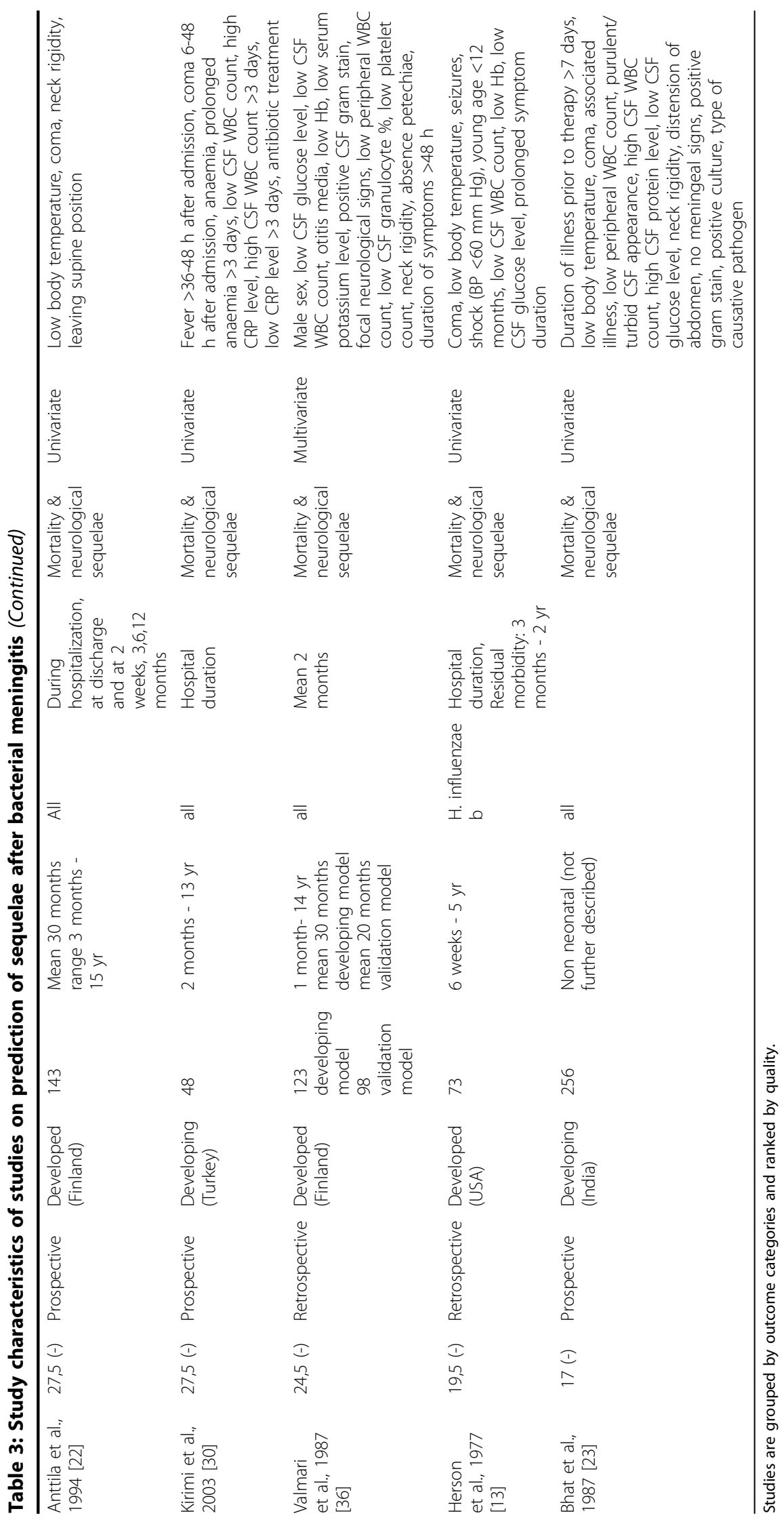


since this study reported several models for different time intervals which was more difficult to compare with other results. There was considerable variation among studies with respect to population size (37 - 716 patients) and follow-up duration (from moment of hospital discharge up to 23 years later). Studies also varied with respect to age at infection (0-17, of which three studies considered specifically neonatal/infant age) and type of causative pathogen studied (varying from describing all types $(n=17)$, to those only studying a specific microorganism ( $\mathrm{n}=9$; mainly Streptococcus pneumoniae)) or more than one but not all microorganisms ( $\mathrm{n}=5$; mainly concerning all microorganisms; however, excluding Haemophilus influenzae type $B$ (HiB)).

\section{Prognostic factors}

Table 4 summarizes the most important prognostic factors for sequelae and death after BM per type of outcome. For mortality and various sequelae together, 75 different possible prognostic factors were identified as significant by the included studies. Many of these factors might be of influence for the prediction of sequelae. However, it is implausible that all of them will be (equally) important. And due to poor study quality, factors not predictive for sequelae or death might have been found as prognostic factors. We therefore considered only those factors found significant in more than one study of moderate/high quality as evidence for being potentially important factors. Results from univariate and multivariate analyses are presented

Table 4 Summary of prognostic factors.

\begin{tabular}{|c|c|c|c|c|c|c|c|c|c|c|}
\hline \multirow[t]{2}{*}{ Prognostic factor } & \multicolumn{4}{|c|}{$\begin{array}{l}\text { Moderate/high quality studies with } \\
\text { multivariate analysis }\end{array}$} & \multicolumn{4}{|c|}{$\begin{array}{c}\text { Moderate/high quality studies with } \\
\text { univariate analysis }\end{array}$} & \multirow{2}{*}{$\begin{array}{c}\begin{array}{c}\text { Low quality } \\
\text { studies with } \\
\text { multivariate } \\
\text { analysis }\end{array} \\
\begin{array}{c}\text { All } \\
\text { outcomes }\end{array}\end{array}$} & \multirow{2}{*}{$\begin{array}{c}\begin{array}{c}\text { Low quality } \\
\text { studies with } \\
\text { univariate } \\
\text { analysis }\end{array} \\
\begin{array}{c}\text { All } \\
\text { outcomes }\end{array}\end{array}$} \\
\hline & $\begin{array}{l}\text { Hearing } \\
\text { loss }\end{array}$ & Mortality & $\begin{array}{l}\text { Neurological } \\
\text { sequelae }\end{array}$ & $\begin{array}{c}\text { Poor } \\
\text { outcome }\end{array}$ & $\begin{array}{c}\text { Hearing } \\
\text { loss }\end{array}$ & Mortality & $\begin{array}{l}\text { Neurological } \\
\text { sequelae }\end{array}$ & $\begin{array}{c}\text { Poor } \\
\text { outcome }\end{array}$ & & \\
\hline $\begin{array}{l}\text { History of } \\
\text { symptoms }>48 \mathrm{~h}\end{array}$ & $1 x$ & & & $1 x$ & & & & & $1 x$ & \\
\hline $\begin{array}{l}\text { Coma/impaired } \\
\text { consciousness }\end{array}$ & & $2 x$ & $2 x$ & $2 x$ & $1 x$ & $4 x$ & $1 x$ & $3 x$ & $1 x$ & $6 x$ \\
\hline Seizures & & $1 x$ & $2 x$ & $2 x$ & & $2 x$ & $1 x$ & $2 x$ & $2 x$ & $4 x$ \\
\hline $\begin{array}{l}\text { Shock/ } \\
\text { hypotension }\end{array}$ & & & & & & $3 x$ & $1 x$ & $2 x$ & & $3 x$ \\
\hline $\begin{array}{l}\text { Peripheral } \\
\text { circulatory failure }\end{array}$ & & $1 x$ & & $1 x$ & & $1 x$ & & & & $1 x$ \\
\hline $\begin{array}{l}\text { Severe respiratory } \\
\text { distress }\end{array}$ & & $1 x$ & & & & $1 x$ & & & & $1 x$ \\
\hline $\begin{array}{l}\text { Prolonged fever } \\
\text { (>7 days) }\end{array}$ & & & $1 x$ & & & & $1 x$ & $1 x$ & & \\
\hline $\begin{array}{l}\text { Seizures }>12 \mathrm{~h} \\
\text { after admission }\end{array}$ & & & & & & $1 x$ & & $2 x$ & $1 x$ & \\
\hline $\begin{array}{l}\text { Low peripheral } \\
\text { WBC count }\end{array}$ & & & & $2 x$ & $1 x$ & $3 x$ & $1 x$ & $2 x$ & $2 x$ & $3 x$ \\
\hline $\begin{array}{l}\text { Low CSF WBC } \\
\text { count }\end{array}$ & & & $1 x$ & $1 x$ & & $1 x$ & $1 x$ & $1 x$ & $2 x$ & $3 x$ \\
\hline $\begin{array}{l}\text { Low CSF glucose } \\
\text { level }\end{array}$ & $2 x$ & & & $1 x$ & & $1 x$ & $1 x$ & $1 x$ & $2 x$ & $6 x$ \\
\hline $\begin{array}{l}\text { High CSF protein } \\
\text { level }\end{array}$ & & $1 x$ & & $1 x$ & $1 x$ & $2 x$ & & $1 x$ & & $4 x$ \\
\hline $\begin{array}{l}\text { S. pneumonia as } \\
\text { causative } \\
\text { pathogen }\end{array}$ & $2 x$ & & $2 x$ & $1 x$ & & & & & & \\
\hline Young age & & & & & & $1 x$ & $1 x$ & $2 x$ & $1 x$ & $1 x$ \\
\hline $\begin{array}{l}<1 \\
\text { years }\end{array}$ & & & & & & $1 x$ & & $1 x$ & $1 x$ & $1 x$ \\
\hline $\begin{array}{l}<2 \\
\text { years }\end{array}$ & & & & & & & $1 x$ & $1 x$ & & \\
\hline Male gender & $1 x$ & & $1 x$ & $1 x$ & & & & & $2 x$ & \\
\hline Fever $>40^{\circ} \mathrm{C}$ & & & $1 x$ & & & $1 x$ & & & & \\
\hline $\begin{array}{l}\text { Absence of } \\
\text { petechiae }\end{array}$ & $1 x$ & & $1 x$ & & & & & & $1 x$ & \\
\hline
\end{tabular}


separately. Factors reported in studies of low quality are reported combined and not per type of outcome.

In total, 17 factors were regarded as showing some evidence of importance in the prediction of sequelae or mortality after BM.

- For hearing loss, the factors S. pneumoniae as a causative pathogen and a low cerebrospinal fluid (CSF) glucose level showed some evidence of being important (i.e. reported in more than one moderate/ high quality study).

- For mortality, coma and seizures were found to be predictive, next to shock, peripheral circulatory failure, severe respiratory distress, a low peripheral white blood cell (WBC) count and a high CSF protein level.

- For neurological sequelae in general, coma, seizures, prolonged fever for at least seven days and a low CSF (WBC) count were considered important risk factors.

Studies reporting on poor outcome, and thereby not differentiating between sequelae or mortality, also reported coma, seizures, shock, a low WBC count both peripheral as well as in CSF and a low CSF glucose level and a high CSF protein level to be important risk factors. Yet they also identified young age (indicated as younger than two years old) and prolonged seizure duration (>12 hours after admission) as important prognostic factors.

When considering all moderate/high quality studies combined, the factors of history of symptoms longer than 48 hours, male gender, fever and absence of petechiae were also found more than once. Although these factors have not been found in more than one study of moderate/high quality for a specific outcome category, they may be important prognostic factors for sequelae or mortality in general.

The 17 identified risk factors were also found in several studies of low quality (see last column of Table 4).

\section{Discussion}

We identified 31 studies in the literature on prognostic factors predicting sequelae or death due to $B M$ in children 0-18 years of age. The included studies have presented a large number of potentially important prognostic factors. Only those factors reported in more than one moderate/high quality study were considered as showing some evidence of being important. These factors included several clinical parameters: coma/impaired consciousness, seizures, shock, peripheral circulatory failure, severe respiratory distress, (prolonged) fever and prolonged duration of seizures, which are all signs of severity during the acute phase of the disease. In addition, the presented factors also included results from diagnostic tests which are performed during admission of the patient in the hospital: low peripheral WBC and low WBC count in CSF, low CSF glucose level and high CSF protein level. These factors are indicators of an acute severe CNS infection and thus are also parameters of severity of the disease.

The presence of these clinical and diagnostic factors in our study demonstrates that severe illness at admission contributes to BM-related mortality and long-term sequelae. In addition, young age was also considered an important prognostic factor. This might be explained by the immature immune status resulting in more severe infections (especially in neonates and children younger than six months) and the developing (and thus more vulnerable) brain of young children. Although it is thought that young children have a higher capability of neurogenesis than older children and adults which leads to better structural repair of brain tissue, and it is known they have a higher plasticity of the brain that allows intact parts to take over functions of damaged areas, early disruption of the developing brain may leads to more functional damage [40-43]. Further, sequelae of meningitis like epilepsy, cerebral palsy and hearing problems can independently cause developmental problems in the young child.

Another prognostic factor which we also demonstrated to be related to severity was the causative pathogen of BM. S. pneumoniae seemed to be an important prognostic factor, suggesting a more pathogenic potency of this species in comparison to other bacteria. This has also been found in other studies presenting association or prognostic models in children or adults $[3,10,44]$. We also found the absence of petechiae to be a prognostic factor. Since petechiae are strongly related with the causative pathogen (occurring mostly in Neisseria meningitidis infections, and much less in S. pneumoniae meningitis), it supports the finding that $S$. pneumoniae is responsible for a non favorable outcome. In studies of high and moderate quality that reported the absence of petechiae as a risk factor, S. pneumoniae was also a prognostic factor of importance. Finally, male gender was found as an important prognostic factor, for which we do not have an explanation. All of these factors might be important to assess in children with BM when trying to identify those at the highest risk for the development of sequelae.

The main concern about the interpretation of the prognostic factors is the fact that due to limited quality of the included studies and heterogeneity of the data it is impossible to perform a meta-analysis and to construct an overall prediction model. 


\section{Limitations}

The search strategy was restricted to full report articles published in English, in journals available in the used electronic databases. This might have led to language or publication bias by missing relevant studies.

The quality of studies was assessed using the QUIPS instrument, designed for prognosis studies addressing all common sources of bias. The QUIPS, however, lacks discriminative power. We defined a scoring algorithm for better discrimination of study quality. This scoring algorithm and cutoff points used to qualify the quality of the studies are quite arbitrary. However, all identified prognostic factors found in the included studies are presented in Table 3, allowing readers to draw their own conclusions.

We encountered some problems in interpreting the results of the studies. Only significant prognostic factors of the original studies were presented in our review. However, lack of statistical significance may be due to lack of power. Furthermore, many studies performed only univariate analysis and the presented factors might not have been found significant if multivariate analysis had been performed.

In our overview of prognostic factors we only stratified per type of outcome. We did not compare other subgroups, thereby ignoring the heterogeneity in all other study characteristics (study design, method of analysis, follow-up duration, population, age at infection, pathogen and country of study). We refrained from this since strata would include too few studies of moderate/ high quality and too many prognostic factors to discriminate between the groups and draw reliable conclusions.

Finally, due to the limited quality of most studies, and the heterogeneous nature of study characteristics and results, the factors found must only be used with caution.

\section{Conclusions}

Several plausible and important prognostic factors for the prediction of sequelae or mortality after BM in childhood were proposed. Because of the limited quality of most studies and the heterogeneous nature of study characteristics and results, findings must be interpreted critically and the prognostic factors found may be used only with caution. This demonstrates that more high quality prognostic studies on factors related to sequelae or death after BM in childhood are clearly needed.

\section{Appendix 1}

The 10 most common causative pathogens of BM according to the Netherlands Reference Laboratory for Bacterial Meningitis [38]:

-Streptococcus pneumoniae
-Neisseria meningitidis

-Haemophilus influenzae type B (HiB)

-Listeria monocytogenes

-Escherichia coli

-Streptococcus agalactiae (Group B Streptococcus, GBS)

-Streptococcus pyogenes

-Staphylococcus aureus

-Coagulase-negative Staphylococcus (CoNS)

-Cryptococcus neoformans

\section{Appendix 2: used search strategies for Medline and Embase \\ Medline}

\#1 search terms on "Bacterial meningitis"

"Meningitis, Bacterial"[Mh] OR "Meningitis, Bacterial/ complications"[Mh] OR "Meningitis, Bacterial/diagnosis"[Mh] OR "Meningitis, Bacterial/epidemiology"[Mh] OR "Meningitis, Bacterial/physiopathology"[Mh] OR "Meningitis, Bacterial/psychology"[Mh] OR "Meningitis, Meningococcal"[Mh] OR "Meningitis, Meningococcal/ complications"[Mh] OR "Meningitis, Meningococcal/ diagnosis"[Mh] OR "Meningitis, Meningococcal/mortality"[Mh] OR "Meningitis, Pneumococcal"[Mh] OR "Meningitis, Pneumococcal/complications"[Mh] OR "Meningitis, Pneumococcal/diagnosis"[Mh] OR "Meningitis, Pneumococcal/mortality"[Mh] OR "Meningitis, Escherichia coli"[Mh] OR "Meningitis, Escherichia coli/ complications"[Mh] OR "Meningitis, Escherichia coli/ diagnosis"[Mh] OR "Meningitis, Escherichia coli/mortality"[Mh] OR "Meningitis, Haemophilus"[Mh] OR "Meningitis, Haemophilus/complications"[Mh] OR "Meningitis, Haemophilus/diagnosis"[Mh] OR "Meningitis, Haemophilus/mortality"[Mh] OR "Meningitis, Listeria"[Mh] OR "Meningitis, Listeria/complications"[Mh] OR "Meningitis, Listeria/diagnosis"[Mh] OR "Meningitis, Listeria/mortality"[Mh] OR meningitis[tw] AND (bacterial[tw] OR meningococcal[tw] OR pneumococcal[tw] OR Neisseria[tw] OR meningitides[tw] OR Streptococcus[tw] OR pneumoniae[tw] OR Haemophilus[tw] OR $\mathrm{Hib}$ [tw] OR influenzae[tw] OR Listeria[tw] OR monocytogenes[tw] OR Escherichia[tw] OR coli[tw] OR agalactiae[tw] OR pyogenes[tw] OR Staphylococcus[tw] OR aureus[tw] OR Cryptococcus[tw] OR neoformans[tw])

\#2 search terms on "prognosis"

Morbidity[Mh:noexp] OR mortality[Mh:noexp] OR "cause of death"[Mh] OR survival rate [Mh] OR prog$\operatorname{nos}^{*}[\mathrm{tw}]$ OR predict*[tw] OR course ${ }^{*}[\mathrm{tw}]$ OR longitudinal[tw] OR follow-up[tw] OR followup[tw] OR follow up [tw] OR cohort*[tw] OR survival[tw] OR cohort studies[mh] OR follow-up studies[mh]

\#3 search terms exclusions

("addresses"[Pt] OR "biography"[Pt] OR “case reports" $[\mathrm{Pt}]$ OR "comment" $[\mathrm{Pt}]$ OR "directory" $[\mathrm{Pt}] \mathrm{OR}$ "editorial” $[\mathrm{Pt}]$ OR "festschrift" [Pt] OR “interview" [Pt] OR "lectures"[Pt] 
OR "legal cases" $[\mathrm{Pt}] \mathrm{OR}$ "legislation" $[\mathrm{Pt}] \mathrm{OR}$ "letter" $[\mathrm{Pt}]$ OR "news" $[\mathrm{Pt}]$ OR "newspaper article" $[\mathrm{Pt}]$ OR "patient education handout" $[\mathrm{Pt}] \mathrm{OR}$ "popular works" $[\mathrm{Pt}] \mathrm{OR}$ "congresses" [Pt] OR "consensus development conference" $[\mathrm{Pt}]$ OR "consensus development conference, nih" [Pt] OR "practice guideline" [Pt]) NOT ("animals"[Mh Terms] NOT "humans"[Mh Terms])

Final search on Bacterial meningitis and prognosis with exclusions

\#1 AND \#2 NOT \#3

\section{Embase}

\section{\#1 search terms on "Bacterial meningitis"}

((('bacterial meningitis'/exp OR 'bacterial meningitis') OR ('epidemic meningitis'/exp OR 'epidemic meningitis')) OR ('meningitis'/de OR 'meningitis') AND (bacterial OR meningococcal OR pneumococcal OR ('neisseria'/de OR 'neisseria') OR meningitides OR ('streptococcus'/de OR 'streptococcus') OR pneumoniae OR ('haemophilus'/ de OR 'haemophilus') OR hib OR influenzae OR ('listeria'/ de OR 'listeria') OR monocytogenes OR ('escherichia'/de OR 'escherichia') OR coli OR agalactiae OR pyogenes OR ('staphylococcus'/de OR 'staphylococcus') OR aureus OR ('cryptococcus'/de OR 'cryptococcus') OR neoformans)). include text word

\section{\#2 search terms on "prognosis"}

((('morbidity'/de OR 'morbidity') OR ('mortality'/de OR 'mortality') OR ('cause of death'/exp OR 'cause of death') OR ('survival rate'/exp OR 'survival rate') OR ('cohort analysis'/exp OR 'cohort analysis') OR ('follow up'/exp OR 'follow up')) OR prognos* OR predict* OR course $^{*}$ OR cohort* OR longitudinal OR ('follow up'/de OR 'follow up') OR ('followup'/de OR 'followup') OR ('survival'/de OR 'survival')). include text word

\section{\#3 search terms exclusions}

(('literature'/exp OR 'literature'/de) OR ('case report'/exp OR 'case report'/de) OR ('directory'/exp OR 'directory'/ de) OR ('editorial'/exp OR 'editorial'/de) OR ('interview'/ exp OR 'interview'/de) OR ('medicolegal aspect'/exp OR 'medicolegal aspect'/de) OR ('reading'/exp OR 'reading'/ de) OR ('publication'/exp OR 'publication'/de) OR ('patient education'/exp OR 'patient education'/de) OR ('organization'/exp OR 'organization'/de) OR ('consensus development'/exp OR 'consensus development'/de) OR ('practice guideline'/exp OR 'practice guideline'/de)) NOT (('animal'/exp OR 'animal'/de) NOT ('human'/exp OR 'human'/de))

Final search Bacterial meningitis and prognosis with exclusions

\#1 AND \#2 NOT \#3

\section{Acknowledgements}

The authors thank Ricky Levitan for her help with the English language. There was no funding.

\section{Author details}

${ }^{1}$ VU University Medical Center, Department of Pediatrics and Infectious Diseases, Amsterdam, The Netherlands. ${ }^{2}$ Emma Children's Hospital Academic Medical Center, University of Amsterdam, Department of Neonatology, Amsterdam, The Netherlands. ${ }^{3} \mathrm{VU}$ University Medical Center, Department of Epidemiology and Biostatistics and the EMGO Institute for Health and Care Research, Amsterdam, the Netherlands.

\section{Authors' contributions}

RdJ, MvF, MW and CT had primary responsibility for protocol development and writing of the manuscript. RdJ and MW were responsible for the selection and quality assessment of the articles and extraction and analysis of the data. RG substantial contributed to the writing of the manuscript. All authors read and approved the final manuscript.

\section{Competing interests}

The authors declare that they have no competing interests.

Received: 11 April 2010 Accepted: 5 August 2010

Published: 5 August 2010

\section{References}

1. Molyneux E, Riordan FA, Walsh A: Acute bacterial meningitis in children presenting to the Royal Liverpool Children's Hospital, Liverpool, UK and the Queen Elizabeth Central Hospital in Blantyre, Malawi: a world of difference. Ann Trop Paediatr 2006, 26:29-37.

2. Saez-Llorens $X$, McCracken GH: Bacterial meningitis in children. Lancet 2003, 361:2139-2148.

3. Theodoridou MN, Vasilopoulou VA, Atsali EE, Pangalis AM, Mostrou GJ, Syriopoulou VP, Hadjichristodoulou CS: Meningitis registry of hospitalized cases in children: epidemiological patterns of acute bacterial meningitis throughout a 32-year period. BMC Infect Dis 2007, 7:101.

4. Baraff $L$, Lee SI, Schriger DL: Outcomes of bacterial meningitis in children: a meta-analysis. Pediatr Infect Dis J 1993, 12:389-394.

5. Koomen I, Grobbee DE, Roord JJ, Jennekens-Schinkel A, van der Lei HD, Kraak MA, van Furth AM: Prediction of academic and behavioural limitations in school-age survivors of bacterial meningitis. Acta Paediatr 2004, 93:1378-1385.

6. Pelkonen $\mathrm{T}$, Roine I, Monteiro L, Correia M, Pitkaranta A, Bernardino L, Peltola H: Risk factors for death and severe neurological sequelae in childhood bacterial meningitis in sub-Saharan Africa. Clin Infect Dis 2009, 48:1107-1110.

7. Koomen I, Grobbee DE, Roord JJ, Donders R, Jennekens-Schinkel A, van Furth AM: Hearing loss at school age in survivors of bacterial meningitis: assessment, incidence, and prediction. Pediatrics 2003, 112:1049-1053.

8. Kornelisse RF, Westerbeek CM, Spoor AB, van der Heijde B, Spanjaard L, Neijens HJ, de Groot R: Pneumococcal meningitis in children: prognostic indicators and outcome. Clin Infect Dis 1995, 21:1390-1397.

9. Woolley AL, Kirk KA, Neumann AM, MCWilliams SM, Murray J, Freind D, Wiatrak BJ: Risk factors for hearing loss from meningitis in children: the Children's Hospital experience. Arch Otolaryngol Head Neck Surg 1999, 125:509-514.

10. Oostenbrink R, Maas M, Moons KG, Moll HA: Sequelae after bacterial meningitis in childhood. Scand J Infect Dis 2002, 34:379-382.

11. Anderson V, Anderson P, Grimwood K, Nolan T: Cognitive and executive function 12 years after childhood bacterial meningitis: effect of acute neurologic complications and age of onset. J Pediatr Psychol 2004, 29:67-81.

12. Grimwood K, Nolan TM, Bond L, Anderson VA, Catroppa C, Keir EH: Risk factors for adverse outcomes of bacterial meningitis. $J$ Paediatr Child Health 1996, 32:457-462.

13. Herson VC, Todd JK: Prediction of morbidity in Hemophilus influenzae meningitis. Pediatrics 1977, 59:35-39.

14. Kutz JW, Simon LM, Chennupati SK, Giannoni CM, Manolidis S: Clinical predictors for hearing loss in children with bacterial meningitis. Arch Otolaryngol Head Neck Surg 2006, 132:941-945.

15. Singhi $P$, Bansal A, Geeta P, Singhi S: Predictors of long-term neurological outcome in bacterial meningitis. Indian J Pediatr 2007, 74:369-374.

16. Akpede GO, Akuhwa RT, Ogiji EO, Ambe JP: Risk factors for an adverse outcome in bacterial meningitis in the tropics: a reappraisal with focus 
on the significance and risk of seizures. Ann Trop Paediatr 1999, 19:151-159.

17. Edwards MS, Rench MA, Haffar AA, Murphy MA, Desmond MM, Baker CJ: Long-term sequelae of group B streptococcal meningitis in infants. J Pediatr 1985, 106:717-722.

18. Forsyth $H$, Kalumbi F, Mphaka E, Tembo M, Mwenechanya J, Kayira K, Bwanaisa L, Njobvu A, Walsh A, Molyneux E: Hearing loss in Malawian children after bacterial meningitis: Incidence and risk factors. Audiological Medicine 2004, 2:100-107.

19. Pagliano P, Fusco U, Attanasio V, Rossi M, Pantosti A, Conte M, Faella FS: Pneumococcal meningitis in childhood: a longitudinal prospective study. FEMS Immunol Med Microbiol 2007, 51:488-495.

20. Pikis A, Kavaliotis J, Tsikoulas J, Andrianopoulos P, Venzon D, Manios S: Long-term sequelae of pneumococcal meningitis in children. Clin Pediatr (Phila) 1996, 35:72-78.

21. Oostenbrink R, Moons KG, Derksen-Lubsen G, Grobbee DE, Moll HA: Early prediction of neurological sequelae or death after bacterial meningitis. Acta Paediatr 2002, 91:391-398.

22. Anttila M: Clinical criteria for estimating recovery from childhood bacterial meningitis. Acta Paediatr 1994, 83:63-67.

23. Bhat BV, Verma IC, Puri RK, Srinivasan S, Nalini P: Prognostic indicators in pyogenic meningitis. Indian Pediatr 1987, 24:977-983.

24. Biesheuvel CJ, Koomen I, Vergouwe $Y$, Van Furth $M$, Oostenbrink R, Moll HA, Grobbee DE, Moons KG: Validating and updating a prediction rule for neurological sequelae after childhood bacterial meningitis. Scand J Infect Dis 2006, 38:19-26.

25. Bortolussi R, Krishnan C, Armstrong D, Tovichayathamrong P: Prognosis for survival in neonatal meningitis: clinical and pathologic review of 52 cases. Can Med Assoc J 1978, 118:165-168.

26. Chao YN, Chiu NC, Huang FY: Clinical features and prognostic factors in childhood pneumococcal meningitis. J Microbiol Immunol Infect 2008, 41:48-53.

27. Fakhir S, Ahmad SH, Ahmad P: Prognostic factors influencing mortality in meningococcal meningitis. Annals of Tropical Paediatrics 1992, 12:149-154.

28. Johnson AWBR, Adedoyin OT, Abdul-Karim AA, Olanrewaju AWl: Childhood pyogenic meningitis: Clinical and investigative indicators of etiology and outcome. Journal of the National Medical Association 2007, 99:937-947.

29. Kaaresen PI, Flaegstad T: Prognostic factors in childhood bacterial meningitis. Acta Paediatr 1995, 84:873-878.

30. Kirimi E, Tuncer O, Arslan S, Atas B, Caksen H, Uner A, Oner AF, Odabas D: Prognostic factors in children with purulent meningitis in Turkey. Acta medica Okayama 2003, 57:39-44.

31. Klinger $\mathrm{G}$, Chin CN, Beyene J, Perlman M: Predicting the outcome of neonatal bacterial meningitis. Pediatrics 2000, 106:477-482.

32. Letson GW, Gellin BG, Bulkow LR, Parks DJ, Ward Jl: Severity and frequency of sequelae of bacterial meningitis in Alaska Native infants. Correlation with a scoring system for severity of sequelae. Am J Dis Child 1992, 146:560-566

33. Lovera $D$, Arbo A: Risk factors for mortality in Paraguayan children with pneumococcal bacterial meningitis. Trop Med Int Health 2005, 10:1235-1241.

34. Pomeroy SL, Holmes SJ, Dodge PR, Feigin RD: Seizures and other neurologic sequelae of bacterial meningitis in children. $N$ Engl J Med 1990, 323:1651-1657.

35. Roine I, Peltola H, Fernandez J, Zavala I, Gonzalez Mata A, Gonzalez Ayala S, Arbo A, Bologna R, Mino G, Goyo J, et al: Influence of admission findings on death and neurological outcome from childhood bacterial meningitis. Clin Infect Dis 2008, 46:1248-1252.

36. Valmari $P$, Makela $M$, Kataja $M$, Peltola $H$ : Multivariate prognostication in bacterial meningitis of childhood. Scand J Infect Dis 1987, 19:29-34.

37. Wasier AP, Chevret L, Essouri S, Durand P, Chevret S, Devictor D: Pneumococcal meningitis in a pediatric intensive care unit: prognostic factors in a series of 49 children. Pediatr Crit Care Med 2005, 6:568-572.

38. Netherlands Reference Laboratory for Bacterial Meningitis: Bacterial meningitis in the Netherlands: annual report 2006. Amsterdam, The Netherlands: AMC/RIVM 2007

39. Hayden JA, Cote P, Bombardier C: Evaluation of the quality of prognosis studies in systematic reviews. Ann Intern Med 2006, 144:427-437.

40. de Jonge RC, Swart JF, Koomen I, Rombouts SA, Gemke RJ, Barkhof F, van Furth AM: No structural cerebral differences between children with a history of bacterial meningitis and healthy siblings. Acta Paediatr 2008, 97:1390-1396.

41. Gerber J, Bottcher T, Hahn M, Siemer A, Bunkowski S, Nau R: Increased mortality and spatial memory deficits in TNF-alpha-deficient mice in ceftriaxone-treated experimental pneumococcal meningitis. Neurobiol Dis 2004, 16:133-138.

42. Tauber SC, Stadelmann C, Spreer A, Bruck W, Nau R, Gerber J: Increased expression of BDNF and proliferation of dentate granule cells after bacterial meningitis. J Neuropathol Exp Neurol 2005, 64:806-815.

43. Yagita Y, Kitagawa K, Ohtsuki T, Takasawa K, Miyata T, Okano H, Hori M, Matsumoto M: Neurogenesis by progenitor cells in the ischemic adult rat hippocampus. Stroke 2001, 32:1890-1896.

44. van de Beek D, de Gans J, Tunkel AR, Wijdicks EF: Community-acquired bacterial meningitis in adults. $N$ Engl J Med 2006, 354:44-53.

\section{Pre-publication history}

The pre-publication history for this paper can be accessed here: http://www.biomedcentral.com/1471-2334/10/232/prepub

doi:10.1186/1471-2334-10-232

Cite this article as: de Jonge et al:: Predicting sequelae and death after bacterial meningitis in childhood: A systematic review of prognostic studies. BMC Infectious Diseases 2010 10:232.

\section{Submit your next manuscript to BioMed Central and take full advantage of:}

- Convenient online submission

- Thorough peer review

- No space constraints or color figure charges

- Immediate publication on acceptance

- Inclusion in PubMed, CAS, Scopus and Google Scholar

- Research which is freely available for redistribution

Submit your manuscript at www.biomedcentral.com/submit
C) Biomed Central 